\title{
A PANDEMIA E A URGÊNCIA DE MEDIDAS PARA INCLUSÃO DIGITAL
}

\section{THE PANDEMIC AND THE URGENCY OF MEASURES FOR DIGITAL INCLUSION}

\author{
Marcela Azarias Rodrigues \\ Thaís e Silva Albani* \\ Daniela Hruschka Bahdur ${ }^{\star \star \star}$
}

\begin{abstract}
Resumo: O presente trabalho busca examinar como a inclusão digital pode ser compreendida como direito atado à dignidade humana, revestindo-se de fundamental importância em um contexto no qual as relações estão cada vez mais dependentes das ferramentas tecnológicas. Intenta-se, ademais, realizar uma abordagem que considere o atual momento de pandemia da doença COVID-19, que tornou a utilização dos aparatos tecnológicos ainda mais necessária para a comunicação e acesso a serviços básicos, como decorrência das medidas de distanciamento social adotadas para o enfrentamento do novo coronavírus. A partir dessa análise, pretende-se constatar algumas formas pelas quais a exclusão digital se manifesta no contexto da pandemia e como se torna essencial o reconhecimento da inclusão digital como direito fundamental. Para tanto, o estudo será desenvolvido por meio do método dedutivo, em uma abordagem qualitativa. Serão realizadas pesquisas bibliográfica e documental, por meio de livros, artigos científicos e dados extraídos de pesquisas correlatas ao tema discutido.
\end{abstract}

Palavras-chave: Inclusão Digital. Era da Informação. Direitos Fundamentais. COVID-19.

Abstract: This paper aims to examine how digital inclusion can be understood as a right attached to human dignity, being grounded in a context in which relationships are increasingly dependent on technological tools. It is also intended to develop an approach that takes into account the current pandemic of COVID-19 disease, which has made the use of technological devices even more necessary for communication and access to basic services, as a result of the social distancing measures adopted to confront the new coronavirus. From this analysis, it is intended to verify some ways in which digital exclusion manifests itself in the context of the pandemic and how it becomes essential to recognize digital inclusion as a fundamental right. For this, the study will be developed through the deductive method, in a qualitative approach. Bibliographic and documental research will be carried out, by means of books, scientific articles and data extracted from research related to the subject discussed herein.

\footnotetext{
Graduanda em Direito pela Universidade Estadual de Londrina. E-mail: azarias_marcela@hotmail.com.

** Graduanda em Direito pela Universidade Estadual de Londrina. E-mail: thais.albani@hotmail.com.

*** Professora colaboradora em Direitos Humanos na Universidade Estadual de Londrina (UEL). Aluna especial de Doutorado em Filosofia em 2019 pela Universidade Estadual de Londrina (UEL). Mestre em Direito Econômico Internacional em 2008, pela LMU-München, Alemanha, validado no Brasil em 2018. Especialista em Direito do Estado (Tributário) em 2017 pela Universidade Estadual de Londrina (UEL). Procuradora para o Brasil do Grupo Prüftechnik AG desde 2011. Advogada. E-mail: danielahru.adv@gmail.com.
} 
Keywords: Digital Inclusion. Information Age. Fundamental Rights. COVID-19.

Recebido em: 11/01/2020. Aceito em: $27 / 11 / 2020$ 


\section{INTRODUÇÃO}

Não há de se duvidar que as inovações tecnológicas e comunicacionais vieram para ficar. A invasão das tecnologias na vida contemporânea é perceptível desde as tarefas mais simples, como conversas entre conhecidos por redes sociais, até as mais complexas, como resolução de grandes litígios por plataformas processuais eletrônicas. Não há como fugir, isso é um fato.

Ocorre, porém, que o acesso a tais ferramentas, como celulares, computadores ou a própria Internet, ainda é muito restrito a uma pequena parcela da população, não apenas por um aspecto puramente financeiro, mas também pela falta de conhecimento para o manejo dessas tecnologias. Essa realidade excludente, que atinge milhares de brasileiros, passou a ser mais visível e ganhar notória relevância a partir das restrições sociais forçadas provocadas pela pandemia da COVID-19.

Com a propagação dessa doença, que inesperadamente invadiu a sociedade e provocou severas transformações na forma das pessoas se relacionarem, percebeuse que muitas das atividades rotineiras precisaram ser exercidas remotamente, por meio da Internet e aparelhos eletrônicos - exemplos são o teletrabalho e o ensino educacional remoto. Na mesma intensidade, foram reveladas as fragilidades na inclusão igualitária e de qualidade dos indivíduos ao meio virtual, de maneira que as pessoas com menos condições socioeconômicas têm vivenciado, dia após dia, enormes dificuldades em exercer suas atividades diárias.

Tendo como plano de fundo esse panorama atual, que assola os indivíduos sem acesso efetivo ao mundo on-line, é que o presente estudo tem como finalidade principal fundamentar porque a inclusão digital deve ser classificada como um direito fundamental implícito. Intenta-se demonstrar, assim, como a violação de tal direito fundamental fere diretamente a dignidade dos indivíduos, tirando-lhes a voz ativa e oportunidade de integração social. Pretende-se, ademais, verificar se já existem iniciativas estatais aptas a incluir digitalmente os cidadãos, de modo efetivo e democrático.

Para tanto, o artigo se divide em três partes. A primeira irá abordar a conjuntura pandêmica atual, com todos os entraves e desafios a ela inerentes, especialmente em termos tecnológicos e comunicacionais. Em seguida, fundamentarse-á a imprescindibilidade de classificar a inclusão digital como um direito fundamental, dada sua fundamentalidade material e estrito vínculo com o princípio da 
dignidade da pessoa humana. Por fim, serão trazidas algumas iniciativas estatais já tomadas a fim de proporcionar a concretização de tal direito, bem como de inúmeros outros dele decorrentes.

\section{AS FERRAMENTAS TECNOLÓGICAS NO CONTEXTO DA PANDEMIA DE COVID-19}

A pandemia da doença COVID-19 alterou significativamente as dinâmicas sociais em todo o mundo. A circulação de um novo vírus (SARS-CoV-2), a partir do final do ano de 2019, sem que houvesse vacina e medicamentos comprovadamente eficazes em prevenir e tratar a doença, respectivamente, impôs a necessidade de se pensar em diferentes meios para atenuar sua transmissão.

A adoção de medidas para isolamento social, inclusive no Brasil, materializadas pelo fechamento temporário de estabelecimentos dedicados às atividades entendidas como não essenciais ou pela fixação de novos horários de funcionamento, pelas campanhas de incentivo a não aglomeração de pessoas, pela implementação do trabalho remoto em diversas instituições públicas e privadas e pela suspensão das atividades escolares de forma presencial, constituiu parte dos esforços empreendidos para refrear o processo de contaminação e evitar, com isso, eventual descontrole na gestão da crise sanitária.

Integrou o conjunto de medidas a elaboração da Resolução n.․ 313, de 19 de março de 2020, pelo Conselho Nacional de Justiça (CNJ), estabelecendo Plantão Extraordinário no âmbito do Poder Judiciário com o intuito de uniformizar o funcionamento dos serviços judiciários nas circunstâncias da pandemia, tendo em vista, ainda, a necessidade de garantir o acesso à justiça (CONSELHO NACIONAL DE JUSTIÇA, 2020a). Para tanto, estabeleceu a suspensão do trabalho realizado de forma presencial nos seguintes termos:

\footnotetext{
Art. 2ํำ Plantão Extraordinário, que funcionará em idêntico horário ao do expediente forense regular, estabelecido pelo respectivo Tribunal, importa em suspensão do trabalho presencial de magistrados, servidores, estagiários e colaboradores nas unidades judiciárias, assegurada a manutenção dos serviços essenciais em cada Tribunal (CONSELHO NACIONAL DE JUSTIÇA, 2020a, p. 4, grifo nosso).
}

A Resolução n.. 329, de 30 de julho de 2020, editada pelo CNJ, destinou-se, por sua vez, a disciplinar a realização de videoaudiências em processos penais e de 
execução penal durante a pandemia e, com isso, dar prosseguimento à prestação jurisdicional. Para tanto, o próprio CNJ disponibilizou plataforma e possibilitou a utilização de outras ferramentas nesse sentido (CONSELHO NACIONAL DE JUSTIÇA, 2020b, p. 04).

Além das alterações promovidas no âmbito do Judiciário, as atividades concernentes ao campo da educação foram especialmente afetadas pelas medidas de contenção ao coronavírus. No que se refere ao ensino superior, as instituições integrantes do sistema federal de ensino, por exemplo, foram autorizadas por meio da Portaria n. 343 , de 17 de março de $2020^{1}$, editada pelo Ministério da Educação (MEC), a substituir as disciplinas presenciais por aulas que utilizassem meios e tecnologias de informação e comunicação (BRASIL, 2020a, p. 39).

É bem visível, portanto, que nesse contexto em que a interação humana realizada de forma presencial é restringida e fortemente não recomendada, a utilização de ferramentas tecnológicas tanto para a comunicação quanto para o acesso a serviços essenciais se tornou indispensável. A transmutação do formato das aulas com a incorporação do ensino remoto e a realização de audiências judiciais por videoconferência são algumas situações que demonstram a imprescindibilidade de aproveitamento das Tecnologias da Informação e Comunicação (TIC) como meio de exercício de outros direitos, como a educação e o acesso à justiça.

O sociólogo espanhol Manuel Castells (2002, p. 67, grifo do autor), responsável por trabalhos voltados ao estudo da sociedade da informação, inclui em seu entendimento a respeito da tecnologia da informação "o conjunto convergente de tecnologias em microeletrônica, computação (software e hardware), telecomunicações/radiodifusão, e optoeletrônica"2. Para o autor, está em curso um processo de transformação tecnológica que se expande de forma exponencial "em razão de sua capacidade de criar interface entre campos tecnológicos mediante uma linguagem digital comum na qual a informação é gerada, armazenada, recuperada, processada e transmitida" (CASTELLS, 2002, p. 68).

\footnotetext{
${ }^{1}$ Posteriormente, a Portaria n.. 343/2020 foi revogada pela Portaria n. 0 544, de 17 de junho de 2020, que manteve, de todo modo, a possibilidade de aulas não presenciais até 31 de dezembro de 2020

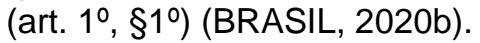

${ }^{2}$ Castells (2002, p. 67) também concebe por tecnologia da informação a engenharia genética. Segundo o sociólogo, "Isso não se deve apenas ao fato de a engenharia genética concentrar-se na decodificação, manipulação e conseqüente reprogramação dos códigos de informação da matéria viva. Deve-se também ao fato de, nos anos 90 , a biologia, a eletrônica e a informática parecerem estar convergindo e interagindo em suas aplicações e materiais e, mais fundalmentalmente, na abordagem conceitual [...]" (CASTELLS, 2002, p. 67).
} 
Compreende-se que os avanços tecnológicos - e as facilidades que eles promovem - contribui para que cada área da vida humana esteja conectada a estas tecnologias e cada vez mais dependente delas. A configuração da sociedade nestes moldes exige, consequentemente, profundas reflexões acerca do acesso individual a essas ferramentas e a forma como poderão ser utilizadas. Assim, de acordo com Almeida (2015, p. 30)

as inovações tecnológicas vêm se tornando cada vez mais imprescindível ao cotidiano e responsável por duas necessidades para quem se habitua a utilizá-la: a obtenção de conteúdo, o que justifica a aquisição de aparelhos, e a produção e compartilhamento de conteúdos. Necessidades estas, que por seu caráter axiológico, são apropriadas pela sociedade, desafiando os envolvidos na produção de normas jurídicas voltadas para o tema. (ALMEIDA, 2015, p. 30).

Se por um lado é notável a indispensabilidade dos recursos tecnológicos como meio de efetiva participação em uma sociedade cada vez mais digital, observase que a utilização dessas ferramentas pelos indivíduos ainda se traduz como um desafio, ante as desigualdades sociais, econômicas e regionais existentes em todo o mundo. Neste sentido, o Relatório Era da interdependência digital: relatório do painel de alto nível sobre cooperação digital do Secretário-Geral da $\mathrm{ONU}^{3}$, traduzido para o português pelo Comitê Gestor da Internet no Brasil, indica que

[...] muitas pessoas ficaram de fora dos benefícios da tecnologia digital. Os dividendos digitais coexistem com as divisões digitais. Bem mais da metade da população mundial ainda não tem acesso de baixo custo à Internet ou está usando apenas uma fração do seu potencial, apesar de estar conectada. ${ }^{8}$ As pessoas que não têm um acesso seguro e de baixo custo às tecnologias digitais são esmagadoramente de grupos que já são marginalizados: mulheres, idosos e portadores de deficiência; grupos indígenas; e aqueles que vivem em áreas pobres, remotas ou rurais. ${ }^{9}$ Muitas desigualdades existentes - em riqueza, oportunidade, educação e saúde - estão sendo ampliadas ainda mais (ORGANIZAÇÃO DAS NAÇÕES UNIDAS, 2020, p. 35).

Especificamente quanto à realidade brasileira, a pesquisa The Inclusive Internet Index, conduzida pela Unidade de Inteligência da The Economist, que analisou a inclusão digital em cem países ao redor do mundo, observando aspectos

\footnotetext{
${ }^{3}$ O Comitê Gestor da Internet no Brasil (2020, online) esclarece que O Painel de Alto Nível Sobre Cooperação Digital do Secretário-Geral da ONU foi estabelecido em 2018 e teve a participação de mais de 4.000 pessoas, representando 104 países. Segundo o Comitê, "O relatório avalia a contribuição das tecnologias digitais para os Objetivos de Desenvolvimento Sustentável, discute a aplicação dos direitos humanos à era digital, identifica lacunas nos mecanismos atuais de cooperação digital global, fornecendo três opções para potenciais novas arquiteturas de cooperação digital global e analisa o papel das Nações Unidas nesse contexto" (COMITÉ GESTOR DA INTERNET NO BRASIL, 2020).
} 
como a disponibilidade (qualidade da infraestrutura disponível para acesso à internet), custo, relevância de conteúdo e facilidade de acesso, ressaltou a alfabetização digital e acessibilidade como pontos fracos do país (THE ECONOMIST INTELLIGENCE UNIT, 2020).

Nota-se, portanto, que as dificuldades de acesso às tecnologias da informação e comunicação já despertavam preocupações em face das transformações operadas na sociedade, responsáveis por torná-las essenciais. No contexto da pandemia, contudo, a primordialidade da inclusão ao mundo digital se aprofunda, uma vez que as ferramentas tecnológicas se tornaram condições para a fruição de serviços.

Sobre o tema, o Instituto de Pesquisa DataSenado realizou, entre os dias 24 a 28 de julho de 2020, através do telefone, entrevistas com 2.400 (dois mil e quatrocentos) brasileiros com dezesseis anos ou mais, valendo-se de dois gruposalvos: o primeiro, de pais que tinham filhos na escola ou faculdade; e o segundo, formado pelos próprios alunos de escolas ou faculdades (DATASENADO, 2020, p. 2).

Pela análise, o Instituto estimou que, aproximadamente, 20 milhões de brasileiros tiveram as aulas suspensas no mês de julho de 2020 (34,78\% do total de alunos matriculados) (DATASENADO, 2020, p. 3). Além destes, outros 32,4 milhões de estudantes de educação superior e educação básica deixaram as aulas presenciais e iniciaram as aulas remotas (DATASENADO, 2020, p. 3).

Após as entrevistas, verificou-se que em torno de "quatro em cada dez brasileiros têm filhos que frequentam escola ou faculdade" (DATASENADO, 2020, p. 8). Do grupo analisado, $20 \%$ afirmou não ter acesso à internet em casa para que os filhos pudessem estudar (DATASENADO, 2020, p. 8). Casos como estes estiveram concentrados em maior proporção nas hipóteses de filhos que estudavam em instituições públicas (DATASENADO, 2020, p. 9).

Por meio das entrevistas realizadas diretamente com os estudantes, constatou-se que " $10 \%$ dos brasileiros com 16 anos ou mais frequentam escola ou faculdade" (DATASENADO, 2020, p. 11). As aulas de $65 \%$ dos alunos que, em condições habituais eram presenciais ou semipresenciais, passaram a ser, em sua maioria, remotas nos trinta dias anteriores (DATASENADO, 2020, p. 13). Considerando os alunos que passaram a ter aulas remotas em razão da pandemia, 13\% afirmaram não possuir internet em casa (DATASENADO, 2020, p. 13), o que, induvidosamente, inviabiliza o real exercício do direito fundamental à educação. 
Ainda sobre o acesso da população aos recursos tecnológicos durante a pandemia, mencione-se a recente pesquisa realizada pelo Centro Regional de Estudos para o Desenvolvimento da Sociedade da Informação (CETIC.BR), dedicado a monitorar a implementação das TICs no país ${ }^{4}$.

O referido Centro, em análise de dados coletados entre 23 de junho e 8 de julho de 2020, registrou um aumento na realização de cursos on-line e de estudos por conta própria por meio da Internet se comparado aos anos de 2018 e 2019, principalmente entre as classes $\mathrm{C}$ e DE e indivíduos com menor escolaridade (CENTRO REGIONAL DE ESTUDOS PARA O DESENVOLVIMENTO DA SOCIEDADE DA INFORMAÇÃO, 2020a, p. 3 e 12). Todavia, constatou-se também que esses grupos ainda se valem dessa possibilidade em menor proporção quando comparados às classes mais altas (CENTRO REGIONAL DE ESTUDOS PARA O DESENVOLVIMENTO DA SOCIEDADE DA INFORMAÇÃO, 2020a, p. 6).

Em uma segunda edição da pesquisa, voltada para a análise da utilização de serviços públicos on-line, com dados colhidos entre 29 de julho e 20 de agosto de 2020, o Centro Regional de Estudos para o Desenvolvimento da Sociedade da Informação (2020b, p. 6) constatou que uma proporção maior de pessoas com "16 anos ou mais buscou informações sobre serviços públicos ou os realizou on-line durante a crise sanitária" se comparado com os dados de 2019. Esses serviços, segundo o estudo, estiveram relacionados, precipuamente, a direitos do trabalhador ou previdenciários, como INSS, seguro-desemprego, auxílio-emergencial e outros (CENTRO REGIONAL DE ESTUDOS PARA O DESENVOLVIMENTO DA SOCIEDADE DA INFORMAÇÃO, 2020b, p. 6).

Quanto à utilização dos serviços de forma on-line, também se verificou aumento se comparado ao ano de 2019. Todavia, neste aspecto, a pesquisa indicou disparidade no acesso a esses serviços, "especialmente entre as pessoas mais vulneráveis aos impactos da crise gerada pelo novo coronavírus" (CENTRO REGIONAL DE ESTUDOS PARA O DESENVOLVIMENTO DA SOCIEDADE DA INFORMAÇÃO, 2020b, p. 06). De forma exemplificativa, tem-se que, no âmbito dos serviços de saúde pública, "apenas uma pequena parte dos usuários com 60 anos ou mais daqueles nas classes DE disseram ter realizado algum serviço de maneira

\footnotetext{
${ }^{4}$ Trata-se de departamento do Núcleo de Informação e Coordenação do Ponto BR (NIC.br), que está ligado ao Comitê Gestor da Internet do Brasil (CGl.br) (CENTRO REGIONAL DE ESTUDOS PARA O DESENVOLVIMENTO DA SOCIEDADE DA INFORMAÇÃO, 2020c).
} 
totalmente remota" (CENTRO REGIONAL DE ESTUDOS PARA O DESENVOLVIMENTO DA SOCIEDADE DA INFORMAÇÃO, 2020b, p. 6).

Assim, observa-se que as tecnologias se revestiram de significativa importância no contexto do distanciamento social impingindo pela pandemia de COVID-19. Se está bastante claro que houve um aumento na utilização da tecnologia da informação e comunicação neste período de excepcionalidades, é também certo que grupos de pessoas, seja por condições socioeconômicas ou pela falta de familiaridade com essas ferramentas, estão excluídas da utilização destes recursos. É tendo este cenário como pano de fundo que se questiona o status do direito à inclusão digital no ordenamento jurídico brasileiro, cuja discussão será apresentada na sequência.

\section{A INCLUSÃO DIGITAL COMO DIREITO FUNDAMENTAL}

Com a difusão das Tecnologias da Informação e Comunicação (TICs) no meio social, alterou-se substancialmente a maneira pela qual as pessoas se relacionam. Essas tecnologias, aliadas à Internet, possibilitaram a redefinição da ideia de espaçotempo, encurtando distâncias físicas outrora intransponíveis. Mais do que isso, proporcionaram também maior democratização e ampliação do acesso à informação, podendo ser consideradas como um instrumento essencial para exercício de participação ativa do indivíduo na sociedade atual (FLAIN, 2017, p. 19).

Enfatiza Dias (2011, p. 80) que a comunicação em rede existe desde que as pessoas começaram a se relacionar em grupos e comunidades, não sendo uma novidade dos tempos hodiernos. A mudança, entretanto, estaria no fato de que, com o advento das ferramentas tecnológicas, as relações foram transpostas às barreiras geográficas e estruturais que antes em muito dificultavam o contato humano. Assim,

[...] o que a internet faz é potencializar a comunicação em rede, expandindoa para nível global, a partir da interconexão de computadores. E, ao criar esse ambiente de comunicação interconectada, permite que todo cidadão que tenha acesso a ele possa trocar informações, pesquisar conteúdos dos mais diferentes tipos e procedências, participar de redes sociais, baixar e subir arquivos, participar de produções em rede, remixar e recriar conteúdos armazenados na rede, enfim, se relacionar, se divertir e produzir nesse novo ambiente (DIAS, 2011, p. 81).

Dentro dessa perspectiva, a humanidade vive um momento histórico no qual as relações em rede estão sendo transformadas e elevadas a outro patamar, compreendendo significativas mudanças sociais, culturais, econômicas, políticas e 
estruturais - o que vem sendo chamado pelos autores de Sociedade da Informação. Esse cenário de inovações e desenvolvimentos proporcionou o fortalecimento de direitos já existentes, como o de liberdade de expressão e opinião, bem como a discussão de novos, como o de acesso à Internet e o direito ao esquecimento (PIOVESAN; QUIXADÁ, 2019, p. 134).

Logo, a relevância da inclusão digital nasce justamente do fato de que, atualmente, parcela significativa das informações e relações sociais são direcionadas às tecnologias, e a obstrução desses meios inviabiliza o exercício de diversos direitos, visto que "coloca o ser humano como agente passivo das movimentações de direitos, tornando-os inalcançáveis. A inclusão digital é a ferramenta que possibilita o reconhecimento e o enfrentamento destas situações" (GONÇALVES, 2011, p. 68).

Não obstante tais considerações, fato indiscutível é a ainda gigante parcela da população brasileira com acesso precário às novas tecnologias virtuais, sendo preocupante a verdadeira dimensão de "excluídos digitais" persistente no Brasil. A desigualdade de acesso a esses meios, que vem sendo denominada de digital divide, gap digital, apartheid digital, infoexclusão, ou exclusão digital, tem proporcionado inúmeros debates acerca da necessidade de formulação de políticas públicas com a finalidade de minimizá-las (BONILLA; OLIVEIRA, 2011, p. 24).

Interessante salientar que tal exclusão não se concretiza somente na dificuldade de acesso às novas tecnologias, mas também naquilo que se denomina de "analfabetismo digital". Trata-se de problema político-social consistente em pessoas não preparadas para o uso das novas tecnologias, tornando a mão de obra obsoleta e acentuando desigualdades sociais já existentes. Sobre o assunto, bem coloca Pinheiro (2015):

O fenômeno de marginalização social se dá pela incapacidade dos indivíduos de conhecer e dominar as novas tecnologias - não basta saber escrever, é preciso saber enviar um e-mail. Ao mesmo tempo que a Era Digital abre maiores possibilidades de inclusão, a exclusão torna-se mais cruel. Aqueles que não tiverem existência virtual dificilmente sobreviverão também no mundo real, e esse talvez seja um dos aspectos mais aterradores dos novos tempos (PINHEIRO, 2015).

A par disso, vê-se não ser possível discorrer sobre inclusão digital sem antes relacioná-la, em sua essência, à ideia de exclusão. Conforme Gonçalves (2011), as expressões "inclusão" e "exclusão" não podem ser separadas, pois: 
Onde há uma necessidade de inclusão há o reconhecimento implícito da exclusão. É no reconhecimento deste duplo conceitual nas práticas históricas, sociais, econômicas e culturais das tecnologias de informação e comunicação, que surgem os questionamentos, os desafios, as ações, as omissões, as lutas, os conflitos (GONÇALVES, 2011, p. 33).

Serau Júnior e Gonçalves (2003, p. 247) explicam que a inclusão digital pode ser compreendida como uma complexa ação oriunda do Governo, do Terceiro Setor e dos particulares que visa atingir, precipuamente, dois objetivos. A primeira finalidade corresponde a promover o acesso de toda a população aos meios tecnológicos, como celulares, computadores e rede física de telecomunicações, para que, a partir disso, possam se conectar à Internet e participar da Sociedade da Informação, ampliando suas perspectivas pessoais e profissionais.

O segundo objetivo, por sua vez, se traduz em educar e ensinar a população sobre a utilização, interação, reconhecimento e domínio das ferramentas tecnológicas, assim como seus benefícios na melhoria de qualidade de vida e de oportunidades (SERAU JÚNIOR; GONÇALVES, 2003, p. 247).

Explica Gonçalves (2011, p. 31) que a expressão "inclusão digital" não é, academicamente, a mais correta, mas deriva de um ambiente de fortes lutas sociais, tendo como eixo central "[...] a busca pela superação das barreiras e obstáculos que são instituídos nas relações sociais e que acabam por gerar as exclusões". Nesse sentido é que o termo proporciona maior percepção acerca das práticas sociais, históricas, culturais e econômicas relativas à necessidade humana de se inserir nas possibilidades das tecnologias da informação e comunicação, bem como dos obstáculos a serem vencidos para tal (GONÇALVES, 2011, p. 31).

Verifica-se, com isso, que a inclusão digital diz respeito não somente ao acesso dos usuários à Internet e aos instrumentos tecnológicos de comunicação, como também à capacitação para utilizar tais recursos, de forma que se tenha "[...] maior foco na inclusão e não no digital" (ALMEIDA, 2015, p. 74). Em um mundo globalizado, com enfoque na comunicação, a inclusão digital não apenas gera o dever ao Estado de promover meios comunicacionais entre os seres humanos, mas, principalmente, o de incluir digitalmente todas as pessoas, como uma condição de sobrevivência em tempos de vida digital (ALMEIDA, 2015, p. 77).

Almeida (2015, p. 75) chama a atenção, nesse sentido, para a importância da inclusão digital de analfabetos, índios, idosos, deficientes físicos e outros grupos que, por questões históricas e sociais, estão excluídas do "público alvo" das grandes 
empresas comerciais da área de tecnologia. Isso ganha especial relevância quando se considera que a inclusão digital é, em realidade, um direito ligado à essência da atual vida em sociedade, de forma que sua não disponibilização a todos gera uma grave violação à dignidade dos indivíduos excluídos.

No ordenamento jurídico brasileiro, a inclusão digital já é reconhecida como um direito em âmbito infraconstitucional. A exemplo, o Marco Civil da Internet (Lei no 12.965/2014) traz, em diversos dispositivos, regras concernentes à necessidade de acesso à Internet e capacitação para o seu uso. Possível citar nesse sentido o artigo 26, pelo qual:

Art. 26. O cumprimento do dever constitucional do Estado na prestação da educação, em todos os níveis de ensino, inclui a capacitação, integrada a outras práticas educacionais, para o uso seguro, consciente e responsável da internet como ferramenta para o exercício da cidadania, a promoção da cultura e o desenvolvimento tecnológico (BRASIL, [2018]).

Com base no exposto até aqui, perceptível que a inclusão digital já ocupa espaço de significativa importância na sociedade atual, de forma a garantir status de direito com obrigatória observância pelo Estado. Entretanto, urge questionar e debater o seguinte: apesar dessa relevância, poderia tal direito ser classificado como fundamental, ainda que não positivado na Constituição de 1988 ?

Analisando a questão aqui posta, Pes (2015, p. 7-8) explica que, para que um direito possa ser classificado como fundamental, ele deverá ser dotado de fundamentalidade formal, adquirida por meio da positivação no texto constitucional, ou "somente" de fundamentalidade material, quando substancialmente atribuído de relevância e essencialidade inseparáveis da própria noção de pessoa, constituindo a base jurídica da vida humana e garantia da dignidade. Explica o autor que:

[...] a fundamentalidade material dos direitos fundamentais está vinculada à caracterização que recebe determinado direito humano de ser reconhecido ou assegurado (expressa ou implicitamente) por determinada Constituição, consistindo em bens ou valores dotados de suficiente relevância e essencialidade a ponto de merecer ou necessitar de uma proteção jurídica e normatividade reforçada, especialmente no que diz respeito à exclusão do âmbito de disponibilidade dos poderes constituídos (PES, 2015, p. 7).

É a partir de tais concepções de fundamentalidade formal e material que Sarlet (2016) constrói e embasa o significado atribuível aos direitos fundamentais, que poderiam ser entendidos como: 
[...] todas as posições jurídicas concernentes às pessoas (naturais ou jurídicas, consideradas na perspectiva individual ou transindividual) que, do ponto de vista do direito constitucional positivo, foram, expressa ou tacitamente, integradas à constituição e retiradas da esfera de disponibilidade dos poderes constituídos, bem como todas as posições jurídicas que, por seu conteúdo e significado, possam Ihes ser equiparadas, tendo, ou não, assento na constituição formal (SARLET, 2016).

Necessário considerar, ademais, que a Constituição Federal de 1988 adota um sistema aberto de regras e princípios, não se restringindo àqueles nela expressos. Essa cláusula aberta do texto constitucional quanto aos direitos fundamentais permite que se leve em consideração não apenas os direitos e as garantias expressamente previstos, como também aqueles advindos dos princípios e do regime adotado, o democrático, bem como dos tratados internacionais de direitos humanos.

Tal previsão está contida no artigo $5^{\circ}, \S 2^{\circ}$, do texto constitucional, segundo o qual "os direitos e garantias expressos nesta Constituição não excluem outros decorrentes do regime e dos princípios por ela adotados, ou dos tratados internacionais em que a República Federativa do Brasil seja parte" (BRASIL, [2020]). Discorrendo sobre essa disposição constitucional, aponta Sarlet:

A norma contida no $\S 2^{\circ}$ do art. $5^{\circ}$ da CF traduz o entendimento de que, além
dos direitos expressamente positivados no capítulo constitucional próprio
(dos direitos e garantias fundamentais), existem direitos que, por seu
conteúdo e significado, integram o sistema da Constituição, compondo, em
outras palavras, na acepção originária do direito constitucional francês, o
assim chamado bloco de constitucionalidade, que não se restringe
necessariamente a um determinado texto ou mesmo conjunto de textos
constitucionais, ou seja, não se reduz a uma concepção puramente formal de
constitucional e de direitos fundamentais. Assim, a despeito do caráter
analítico do Título II da CF, onde estão contidos os direitos e garantias como
tal designados e reconhecidos pelo constituinte, cuida-se de uma
enumeração não taxativa. O art. $5^{\circ}, \S 2^{\circ}$, da CF, representa, portanto, uma
cláusula que consagra a abertura constitucional de direitos fundamentais
como sendo um sistema inclusivo e amigo dos direitos fundamentais
(SARLET, 2018). Hartmann (2017, p. 16) bem salienta que, ao tempo de elaboração da Constituição de 1988, a Internet e demais tecnologias comunicacionais ainda não representavam à sociedade meios indispensáveis para satisfação das legítimas necessidades do povo. Dessa forma, ainda que extremamente protetivo, o texto constitucional não necessitou incluir a salvaguarda de tais ferramentas em seu rol de direitos e garantias previstos no artigo $5^{\circ}$.

Não obstante tal fato, tem-se que a sociedade é dinâmica, sendo essencial reconhecer que os direitos fundamentais devem permanecer em constante processo de formação, acompanhando os avanços da humanidade, inclusive tecnológicos 
(RIBEIRO apud HARTMANN, 2017, p. 16). Forçoso reconhecer, nesse sentido, que isso é possível justamente pela abertura sistêmica do artigo $5^{\circ}$, $\S 2^{\circ}$, da Constituição.

Entende-se, a partir disso, que a classificação de um direito como fundamental não dependeria, necessariamente, de sua positivação constitucional, e sim, em grande modo, de seu conteúdo. Mister salientar que esses direitos guardam, em sua essência, íntima relação com a dignidade humana, entendida como seu núcleo essencial, de maneira que "[...] qualquer direito que estiver em conexão imediata com a dignidade humana pode ser qualificado como fundamental" (PES, 2015, p. 4). Para Cunha Júnior (2015), tal fato decorre diretamente do reconhecimento da dignidade da pessoa humana como um dos fundamentos da República Federativa do Brasil (artigo 1ํㅡ. III, da Constituição).

Dessarte, para a caracterização da inclusão digital como direito fundamental, necessário, antes de mais nada, justificar sua fundamentalidade material, ante a abertura sistêmica da Constituição para o reconhecimento de direitos fundamentais implícitos. Para Pes (2015, p. 12), os argumentos possíveis para tal enquadramento são encontrados "[...] no conteúdo abrangido pelo princípio da dignidade humana, com a sua garantia precípua de limitar o poder e tutelar a liberdade e a igualdade".

Dessa forma, o acesso às tecnologias da informação e da comunicação, em suas mais variadas formas e contextos, e como forma de exercício da inclusão digital, representaria um direito essencial ligado ao resguardo e à promoção da dignidade. $\mathrm{O}$ titular desse direito, ao ser impedido de exercê-lo, teria o seu direito fundamental violado, ante o desrespeito e desconsideração a sua dignidade (PES, 2015, p. 12). Assevera ainda o autor que:

[...] o direito de acesso às novas tecnologias da informação e comunicação é um direito humano que deve ser reconhecido como materialmente fundamental. É um direito que, na sua dimensão subjetiva, refere-se a interesses e carências que são tão fundamentais que a necessidade de respeito, proteção ou fomento se deixa fundamentar pelo direito, ao ponto de sua não satisfação significar grave sofrimento (atinge a dignidade humana), podendo significar, também, a perda da autonomia do ser (PES, 2015, p. 13).

Para Almeida (2015, p. 92), de forma semelhante, o viés que possibilita justificar, do ponto de vista material, um direito fundamental à inclusão digital é o reconhecimento desta inclusão como parte integrante do patrimônio jurídico das pessoas e que Ihes garante, em alguma medida, proteção à dignidade. Para o autor, 
A inclusão digital não é mais tão-somente uma necessidade humana. Mas, isto sim, um valor que permite ao ser humano o acesso a formas de se realizar como tal, levando à efetivação de outros direitos inerentes à sua condição, tais como a dignidade, a igualdade, a liberdade de expressão e de acesso à informação (ALMEIDA, 2015, p. 92).

Possível ratificar a ideia, assim, de que o núcleo essencial do direito à inclusão digital seria, em grande parte, a própria dignidade humana, já que ela é o princípio basilar e fundante de todo o ordenamento jurídico e, como tal, também o é em relação à inclusão digital. Porém, isso não se dá de forma exclusiva, uma vez que é possível conceber a inclusão digital, também, a partir da educação e do objetivo de pleno desenvolvimento da pessoa (ALMEIDA, 2015, p. 96).

Essa ideia se desencadearia no entendimento de que a inclusão digital não seria exatamente um desdobramento da dignidade, e sim sua própria materialização (ALMEIDA, 2015, p. 97). Com isso,

[...] adotando-se a ideia de que o núcleo essencial do direito fundamental à inclusão digital está na dignidade humana, deve-se buscar uma aplicação máxima de tal princípio a ponto de permitir que a inclusão digital seja capaz de conceder dignidade à pessoa, mais ainda, a aplicação máxima da dignidade humana deve, com base em Alexy, considerar estar incluído digitalmente como condição de dignidade. (ALMEIDA, 2015, p. 100).

Nessa conjuntura protetiva, para Flain (2017, p. 82) é possível compreender a inclusão digital como um direito fundamental viabilizador de outros direitos fundamentais, como a liberdade de expressão, acesso à informação e exercício da cidadania. Isso ocorreria pois:

[...] a inclusão digital, como um direito fundamental ligado à dignidade da pessoa humana, deve ser vislumbrada, também, como um direito-meio. Direito-meio, em decorrência da possibilidade de o princípio da dignidade humana ser uma condição e se irradiar, fundamentando todos os demais direitos e, em função da indivisibilidade e interdependência, importantes características dos direitos fundamentais, que justificam essa ideia (FLAIN, 2017, p. 82).

Nesse sentido, inclusão digital seria "[...] um direito-meio ou direito-garantia dos direitos humanos fundamentais. Direito-meio ou direito-garantia é o caso de um direito acessório a outro direito do qual depende intrinsecamente" (GONÇALVES, 2011, p. 76). Desse modo, contribuiria para o funcionamento de outros direitos fundamentais, a partir do momento em que estes são atingidos por novas ideias e discursos correlatos às novas tecnologias informacionais (GONÇALVES, 2011, p. 74). 
Complementa Pes (2015, p. 1-2), ao dizer que, na contemporânea Sociedade da Informação, boa parte das relações se dá por meios virtuais, sendo a inclusão um direito facilitador do exercício de outros direitos em determinadas circunstâncias, como ocorre com o direito à prestação jurisdicional.

Para Almeida (2015, p. 82), muito mais substancial do que considerar a inclusão digital como um mero direito-meio, seria colocá-la no patamar de um direitofim. Como tal, ela não deve ser assegurada pelo Estado somente por viabilizar outros direitos, como a comunicação e a participação social dos indivíduos, mas porque, indo mais além, contempla a própria condição humana, como pressuposto de vida digna e desenvolvimento humano.

Evidencia Gonçalves (2011, p. 77), por essa perspectiva, o fato de que o direito fundamental à inclusão digital não ocupa mera posição secundária no ordenamento pátrio, dependendo de outro direito para existir. Em contrário, é um direito que "[...] entra em cena para fazer com que eles [demais direitos fundamentais] se tornem relevantes novamente, tenham um sentido, uma efetividade". Assim, "a necessidade de reverberação de conhecimentos, informações e opiniões é extensão do falar, do se comunicar, e com as tecnologias de informação e comunicação tudo fica mais perto, mais fácil e interconectado", tudo por meio do direito à inclusão digital (GONÇALVES, 2011, p. 77).

Não há que se olvidar, dessarte, que a inclusão digital faz parte do rol de direitos fundamentais implícitos, seja como viabilizadora de outros direitos ou como um fim em si mesma, evidenciando as novas formas de relacionamento social e integrações com as tecnologias. Como tal, deve ser assegurada pelo Estado, o qual deve promover sua efetivação, como condição de existência dos indivíduos e materialização da dignidade.

\section{MEDIDAS INICIADAS RUMO À INCLUSÃO DIGITAL}

Como trabalhado no tópico anterior, o direito à inclusão digital se constitui, hodiernamente, como elemento basilar para se pensar em diversos direitos fundamentais. É diante dessa perspectiva que a inclusão digital, por si mesma, pode ser compreendida como um direito fundamental implícito no ordenamento jurídico brasileiro. 
Dado seu caráter fundamental, exsurge a necessidade imperiosa de redução das dificuldades e desigualdades que afetam o acesso às TICs, como forma de promover real democratização do uso dessas ferramentas. Pela natureza deste direito, cabe ao Estado promover políticas com essa finalidade. É que, como leciona Bobbio (2000, p. 504), o reconhecimento dos direitos sociais "requer a intervenção direta do Estado, tanto que são denominados também 'direitos de prestação', exatamente porque exigem, diferentemente dos direitos de liberdade, que o Estado intervenha com providências adequadas".

Neste aspecto, importante destacar o já mencionado Relatório Era da interdependência digital: relatório do painel de alto nível sobre cooperação digital do Secretário-Geral da ONU, que ao almejar economias e sociedade mais inclusivas, recomenda que

[...] até 2030, todos os adultos tenham acesso a redes digitais a preços acessíveis, bem como a serviços financeiros e de saúde habilitados por tecnologias digitais, como forma de dar uma contribuição substancial para a consecução dos ODS [Objetivos de Desenvolvimento Sustentável]. A prestação desses serviços deve evitar abusos, baseando-se em princípios e boas práticas emergentes, um exemplo dos quais é a possibilidade de poder optar por entrar e sair de um serviço, e incentivando o discurso público informado (ORGANIZAÇÃO DAS NAÇÕES UNIDAS, 2020, p. 27).

É nesse cenário de imprescindibilidade das TICs, que se vislumbram algumas tentativas de reconhecimento e concretização do direito à inclusão digital, que extrapole o âmbito doutrinário para encontrar respaldo e disciplina na legislação.

Nesta toada, mencione-se duas propostas de emenda à Constituição que intentavam incluir o direito à Internet no texto constitucional. A primeira, tratava-se da proposta de Emenda Constitucional n. 06/2011, de autoria do Senador Rodrigo Rollenberg (PSB/DF), que buscava alterar o artigo 6 da Constituição para acrescer o direito ao acesso à Rede Mundial de Computadores (Internet) (BRASIL, 2011). A tramitação, contudo, já foi encerrada e a proposta foi arquivada.

Em segundo, cite-se a Proposta de Emenda Constitucional n.ํ 185/2015, elaborada pela deputada Renata Abreu - PTN/SP, que visa acrescentar um novo inciso no art. $5^{\circ}$ da Constituição, a fim de "assegurar a todos acesso universal a Internet entre os direitos fundamentais do cidadão" (BRASIL, 2015). Esta proposta ainda está em tramitação. 
Além das propostas de emenda à Constituição, tem-se, ainda, o Projeto de

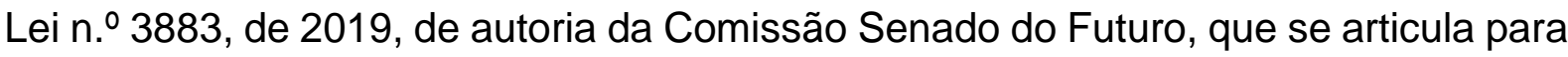
assegurar

[...] aos usuários o acesso contínuo e gratuito aos serviços públicos digitais considerados essenciais, inclusive nos planos de serviço com franquia. Permite que os recursos do Fundo de Universalização dos Serviços de Telecomunicações (Fust) sejam utilizados para financiar políticas públicas de inclusão digital, de massificação do acesso aos serviços de interesse coletivo prestados em regime privado e de acesso a serviços públicos digitais considerados essenciais (BRASIL, 2019).

No período da pandemia, é igualmente verificável ações para contornar os obstáculos oriundos da falta de inclusão digital, promovidas, especialmente, no âmbito

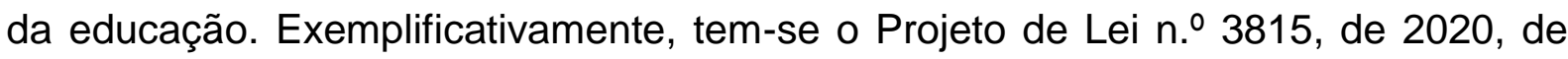
autoria da deputada Tereza Nelma (PSDB-AL), que prevê um "auxílio inclusão digital", no valor de $R \$ 70$, destinado a estudantes da rede pública de educação básica, a fim de proporcionar o acesso a conteúdo educacional constante na Internet (BRASIL, 2020c).

Outras medidas foram adotadas diretamente por Universidades, como o programa "Auxílio-emergencial de Inclusão Digital", lançado pela Universidade Estadual do Maranhão (2020), para disponibilização de SIM CARDS com vistas a possibilitar o acesso de estudantes em situação de vulnerabilidade à internet. A Universidade Estadual de Londrina (2020), por sua vez, deu início a uma campanha para arrecadação de tablets destinados aos estudantes com este mesmo perfil.

Trata-se de passos de extrema relevância no que concerne à inclusão digital e que deve se aliar a políticas públicas de caráter permanente, capazes de proporcionar uma evolução no acesso e manejo destas tecnologias, que cada vez mais se tornarão requisitos para plena participação em sociedade.

\section{CONSIDERAÇÕES FINAIS}

A pandemia de COVID-19 tornou ainda mais evidente as dificuldades relacionadas ao acesso às tecnologias da informação e comunicação. Tal fato se deve, principalmente, pelas medidas adotadas para controle da pandemia no país, que exigiram a realização de diversas atividades a partir de meios não presenciais, como forma de evitar o contato entre os indivíduos. 
Deste modo, o estudo ora realizado verificou, através de pesquisas produzidas no contexto da pandemia pelo DataSenado e Cetic.br, que, apesar do crescimento na utilização de ferramentas tecnológicas para realização de cursos, para participação em aulas em instituições de ensino básico e superior e para fruição de serviços, é notável a existência de parcela da população impedida de se valer dessas mesmas possibilidades por não possuírem condições de acesso.

É neste contexto que se perquiriu a respeito do status que a inclusão digital deve ter no ordenamento jurídico brasileiro. Uma vez que as atuais circunstâncias promoveram a indispensabilidade das TICs, questionou-se a possibilidade deste direito ser entendido como fundamental, muito embora não conste expressamente no texto constitucional.

A análise doutrinária realizada quanto a este aspecto permitiu compreender que os direitos fundamentais não se encerram nos expressamente contidos na Constituição. É preciso observar o conteúdo dos demais direitos que, quando entrelaçado com um dos fundamentos da República Federativa do Brasil - a dignidade da pessoa humana -, poderá, por consequência, ser entendido como fundamental.

São com estas noções que se defendeu a inclusão digital como direito fundamental, já que seria uma forma de promover a dignidade da pessoa humana, possibilitando o acesso dos indivíduos a um universo de informação, bens e serviços alcançados com muito mais facilidade através dos recursos tecnológicos. É a partir dessa perspectiva que se entende a inclusão digital como um meio de concretização de outros tantos direitos, o que reforça a necessidade de reconhecimento de seu caráter fundamental.

Ao final, verificou-se que medidas no âmbito do Legislativo, ligadas à tentativa de alteração do texto constitucional ou criação de projetos de leis que visam ampliar as possibilidades de inclusão, principalmente relacionadas ao acesso à internet, já foram iniciadas. Além disso, no contexto da pandemia, percebeu-se a tomada de medidas emergenciais como forma de promover a inclusão digital e, com isso, possibilitar a fruição de outros direitos fundamentais, como a educação. Como visto, trata-se de medidas tomadas no contexto de emergência, mas que devem, dada a essencialidade da inclusão digital, constituir um caminho para iniciativas cada vez mais enérgicas. 


\section{REFERÊNCIAS}

ALMEIDA, Leonardo Góes de. A inclusão digital como direito fundamental não expresso. 2015. 105 f. Dissertação (Mestrado em Ciência Jurídica) - Universidade Estadual do Norte do Paraná, Jacarezinho, 2015. Disponível em: https://uenp.edu.br/pos-direito-teses-dissertacoes-defendidas/direitodissertacoes/6857-leonardo-goes-de-almeida/file. Acesso em: 22 out. 2020.

BOBBIO, Norberto. Teoria geral da política: a filosofia política e as lições dos clássicos. Rio de Janeiro: Campus, 2000.

BONILLA, Maria Helena Silveira; OLIVEIRA, Paulo Cezar Souza de. Inclusão digital: ambiguidades em curso. In: BONILLA, Maria Helena Silveira; PRETTO, Nelson De Luca (Org.). Inclusão digital: polêmica contemporânea. Salvador: EDUFBA, 2011. v. 2. p. 23-48.

BRASIL. [Constituição (1988)]. Constituição da República Federativa do Brasil de 1988. Brasília, DF: Presidência da República, [2020]. Disponível em: http://www.planalto.gov.br/ccivil_03/constituicao/constituicao.htm. Acesso em: 26 out. 2020.

BRASIL. Lei no 12.965, de 23 de abril de 2014. Estabelece princípios, garantias, direitos e deveres para o uso da Internet no Brasil. Brasília, DF: [2018]. Presidência da república, 20Disponível em: http://www.planalto.gov.br/ccivil_03/_ato20112014/2014/lei//12965.htm. Acesso em: 28 out. 2020.

BRASIL. Portaria no 343 , de 17 de março de 2020. Dispõe sobre a substituição das aulas presenciais por aulas em meios digitais enquanto durar a situação de pandemia do Novo Coronavírus - COVID-19. Diário Oficial da União: seção 1, Brasília, DF, n. 53, p. 39, 18 mar. 2020a. Disponível em:

https://www.in.gov.br/en/web/dou/-/portaria-n-343-de-17-de-marco-de-2020248564376. Acesso em: 25 out. 2020.

BRASIL. Portaria no 544, de 16 de junho de 2020. Dispõe sobre a substituição das aulas presenciais por aulas em meios digitais, enquanto durar a situação de pandemia do novo coronavírus - Covid-19, e revoga as Portarias MEC ํㅡㄴ 343, de 17 de março de 2020, no 345, de 19 de março de 2020, e ํㅜ 473, de 12 de maio de 2020. Diário Oficial da União: seção 1, Brasília, DF, n. 114, p. 62, 17 jun. 2020 b. Disponível em: https://www.in.gov.br/en/web/dou/-/portaria-n-544-de-16-de-junho-de2020-261924872. Acesso em: 25 out. 2020.

BRASIL. Projeto de Lei no 3883, de 2019. Senado Federal. Brasília, DF, 2019. Disponível em: https://www25.senado.leg.br/web/atividade/materias//materia/137584. Acesso em: 30 out. 2020.

BRASIL. Projeto de Lei no 3815, de 2020. Brasília, DF: Câmara dos Deputados, 2020c. Disponível em: https://www.camara.leg.br/propostas-legislativas/2257802. Acesso em: 29 out. 2020. 
BRASIL. Proposta de Emenda à Constituição n 6, de 2011. Brasília, DF: Câmara dos Deputados, 2011. Disponível em:

https://www25.senado.leg.br/web/atividade/materias/-/materia/99334. Acesso em: 30 out. 2020.

BRASIL. Proposta de Emenda à Constituição $n^{\circ}$ 185, de 2015. Brasília, DF:

Câmara dos Deputados, 2015. Disponível em:

https://www.camara.leg.br/proposicoesWeb/fichadetramitacao?idProposicao=207591

5. Acesso em: 30 out. 2020.

CASTELLS, Manuel. A sociedade em rede. 6. ed. rev. amp. Tradução de Roneide Venancio Majer com a colaboração de Klauss Brandini Garhardt. São Paulo: Paz e Terra, 2002.

CENTRO REGIONAL DE ESTUDOS PARA O DESENVOLVIMENTO DA SOCIEDADE DA INFORMAÇÃO. Painel TIC COVID-19: pesquisa sobre o uso da Internet no Brasil durante a pandemia do novo coronavírus. Atividades na Internet, Cultura e Comércio Eletrônico, 1. ed. São Paulo, 13 ago. 2020a. Disponível em: https://cetic.br/media/docs/publicacoes/2/20200817133735/painel_tic_covid19_1edic ao_livro\%20eletr\%C3\%B4nico.pdf. Acesso em: 21 ago. 2020.

\section{CENTRO REGIONAL DE ESTUDOS PARA O DESENVOLVIMENTO DA} SOCIEDADE DA INFORMAÇÃO. Painel TIC COVID-19: pesquisa sobre o uso da Internet no Brasil durante a pandemia do novo coronavírus. Serviços públicos online, telessaúde e privacidade. 2. ed. São Paulo, 01 out. 2020b. Disponível em: https://cetic.br/media/docs/publicacoes/1/20201001085713/painel_tic_covid19_2edic ao_livro\%20eletr\%C3\%B4nico.pdf. Acesso em: 25 out. 2020.

CENTRO REGIONAL DE ESTUDOS PARA O DESENVOLVIMENTO DA SOCIEDADE DA INFORMAÇÃO. Sobre o Cetic.br. São Paulo: cetic.br, 2020c. Disponível em: https://cetic.br/pt/sobre/. Acesso em: 29 out. 2020.

COMITÊ GESTOR DA INTERNET NO BRASIL. CGI.br lança "A Era da Interdependência Digital”' em português, livro com relatório completo do Painel de Alto Nível da ONU. São Paulo, 03 set. 2020. Disponível em: https://www.cgi.br/noticia/releases/cgi-br-lanca-a-era-da-interdependencia-digital-emportugues-livro-com-relatorio-completo-do-painel-de-alto-nivel-da-onu/. Acesso em: 26 out. 2020.

CONSELHO NACIONAL DE JUSTIÇA (Brasil). Resolução ํㅜ 313, de 19 de março de 2020. Estabelece, no âmbito do Poder Judiciário, regime de Plantão Extraordinário, para uniformizar o funcionamento dos serviços judiciários, com o objetivo de prevenir o contágio pelo novo Coronavírus - Covid-19, e garantir o acesso à justiça neste período emergencial. Diário da Justiça. Brasília, DF, n. 71, p. 3-5, 19 mar. 2020a. Disponível em: https://atos.cnj.jus.br/atos/detalhar/3249. Acesso em: 26 out. 2020 .

CONSELHO NACIONAL DE JUSTIÇA (Brasil). Resolução nำ329, de 30 de julho de 2020. Regulamenta e estabelece critérios para a realização de audiências e outros atos processuais por videoconferência, em processos penais e de execução penal, 
durante o estado de calamidade pública, reconhecido pelo Decreto Federal no 06/2020, em razão da pandemia mundial por Covid-19. Diário da Justiça. Brasília, DF, n. 247, p. 2-7, 31 jul. 2020b. Disponível em:

https://atos.cnj.jus.br/atos/detalhar/3400. Acesso em: 26 out. 2020.

CUNHA JÚNIOR, Dirley. A natureza material dos direitos fundamentais. Revista Brasil Jurídico, Salvador, 2015. Disponível em:

https://brasiljuridico.com.br/artigos/a-natureza-material-dos-direitos-fundamentais.por-dirley-da-cunha-junior. Acesso em: 22 out. 2020.

DATASENADO. Pesquisa DataSenado: educação durante a pandemia. Brasília, DF: Senado Federal, 2020. Disponível em:

https://www12.senado.leg.br/institucional/datasenado/arquivos/cerca-de-20-milhoesde-brasileiros-tiveram-aulas-suspensas-em-julho-de-2020. Acesso em: 25 ago. 2020.

DIAS, Lia Ribeiro. Inclusão digital como fator de inclusão social. In: BONILLA, Maria Helena Silveira; PRETTO, Nelson De Luca (Org.). Inclusão digital: polêmica contemporânea. Salvador: EDUFBA, 2011. v. 2. p. 61-90.

FLAIN, Valdirene Silveira. A inclusão digital como direito fundamental passível de viabilizar a participação cidadã. 2017. Dissertação (Mestrado em Direito) Universidade Federal de Santa Maria, Santa Maria, 2017. Disponível em: https://repositorio.ufsm.br/bitstream/handle/1/12541/DIS_PPGDIREITO_2017_FLAIN _VALDIRENE.pdf?sequence=1\&isAllowed=y. Acesso em: 21 ago. 2020.

GONÇALVES, Victor Hugo Pereira. Inclusão digital como direito fundamental. 2011. 135 f. Dissertação (Mestrado em Direito) - Universidade de São Paulo, São Paulo, 2011. Disponível em: https://www.teses.usp.br/teses/disponiveis/2/2140/tde30102012092412/publico/VICTOR_HUGO_PEREIRA_GONCALVES_dissertacao_USP.pdf. Acesso em: 21 ago. 2020.

HARTMANN, Ivar Alberto Martins. O acesso à internet como direito fundamental. In: PORTAL de e-governo, inclusão digital e sociedade do conhecimento. [S. I.], 12 jun. 2017. Disponível em: https://egov.ufsc.br/portal/conteudo/o-acesso-\%C3\%A0internet-como-direito-fundamental-0. Acesso em: 22 nov. 2020. Extraído do Trabalho de Conclusão de Curso apresentado à Faculdade de Direito da Pontifícia Universidade Católica do Rio Grande do Sul. Banca examinadora composta pelo orientador Prof. Dr. Ingo W. Sarlet, Prof ${ }^{\text {. }}$. Me. Fernanda Medeiros, e Prof. Dr. Carlos Alberto Molinaro, em 05 de junho de 2007.

ORGANIZAÇÃO DAS NAÇÕES UNIDAS. Era da interdependência digital: relatório do painel de alto nível sobre cooperação digital do Secretário-Geral da ONU. Núcleo de Informação e Coordenação do Ponto Br, Painel de Alto Nível sobre Cooperação Digital do Secretário-Geral da ONU. Tradução de Ana Zuleika Pinheiro Machado. São Paulo: Comitê Gestor da Internet no Brasil, 2020. Disponível em: https://cgi.br/media/docs/publicacoes/1/20200901150023/CadernoCGlbr_A_era_da_i nterdependencia_digital.pdf. Acesso em: 26 out. 2020. 
PES, João Hélio Ferreira. O direito fundamental implícito de acesso às novas tecnologias da informação e comunicação. In: CONGRESSO INTERNACIONAL DE DIREITO E CONTEMPORANEIDADE: MÍDIAS E DIREITOS DA SOCIEDADE EM REDE, 3., 2015, Santa Maria. Anais [...]. Santa Maria: Universidade Federal de Santa Maria, 2015. Disponível em:

http://coral.ufsm.br/congressodireito/anais/2015/6-11.pdf. Acesso em: 28 out. 2020.

PINHEIRO, Patrícia Peck. Sociedade Digital. In: PINHEIRO, Patrícia Peck. Direito Digital. 6. ed. São Paulo: Saraiva, 2015. ISBN: 9788502635616.

PIOVESAN, Flávia; QUIXADÁ, Letícia. Internet, direitos humanos e sistema de justiça. Revista de Direito Constitucional e Internacional, v. 116, p. 133-153, nov./dez. 2019.

SARLET, Ingo Wolfgang. Art. $5^{\circ}, \S 2^{\circ}$ Os direitos e garantias expressos nesta Constituição não excluem outros decorrentes do regime e dos princípios por ela adotados, ou dos tratados internacionais em que a República Federativa do Brasil seja parte. In: CANOTILHO, José Joaquim Gomes et al. (Coord.). Comentários à constituição do Brasil. 2. ed. São Paulo: Saraiva, 2018. ISBN: 9788553602360.

SARLET, Ingo Wolfgang. Teoria geral dos direitos fundamentais. In: SARLET, Ingo Wolfgang; MARINONI, Luiz Guilherme; MITIDIERO, Daniel. Curso de direito constitucional. 5. ed. São Paulo: Saraiva, 2016. ISBN: 9788547204587.

SERAU JÚNIOR, Marco Aurélio; GONÇALVES, Victor Hugo Pereira. A “inclusão digital" e os direitos sociais perante a realidade da internet: a busca da igualdade material. Revista Brasileira de Direito Constitucional, n. 2, p. 243-253, jul./dez. 2003. Disponível em: http://esdc.com.br/seer/index.php/rbdc/article/view/49. Acesso em: 23 out. 2020.

THE ECONOMIST INTELLIGENCE UNIT. The Inclusive Internet Index. [S. I.]: The Economist Group, 2020. Disponível em:

https://theinclusiveinternet.eiu.com/explore/countries/performance?category=overall. Acesso em: 23 nov. 2020.

UNIVERSIDADE ESTADUAL DE LONDRINA. UEL lança campanha de arrecadação de tablets para inclusão digital. Londrina: UEL, 2020. Disponível em: http://www.uel.br/com/agenciaueldenoticias/index.php?arq=ARQ_not\&id=30540. Acesso em: 20 ago. 2020.

UNIVERSIDADE ESTADUAL DO MARANHÃO. UEMA lança o Auxílio Emergencial de Inclusão Digital. 2020. São Luís: UEMA, 2020. Disponível em: https://www.uema.br/2020/07/uema-lanca-o-auxilio-emergencial-de-inclusao-digital/. Acesso em: 20 ago. 2020. 